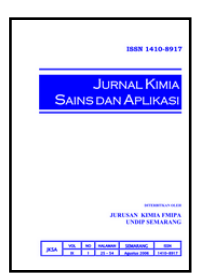

\title{
Sintesis Mikropartikel Kitosan dengan Proses Gelasi Ionik sebagai Adsorben Logam Cd(II)
}

\author{
Heru Witoyo Putra ${ }^{a}$, Khabibi $^{\mathrm{a}^{*}}$ \\ a Analytical Chemistry Laboratory, Chemistry Department, Faculty of Sciences and Mathematics, Diponegoro University, Jalan Prof. \\ Soedarto, Tembalang, Semarang \\ * Corresponding author: khabibi@live.undip.ac.id
}

\section{Article Info}

Keywords:

Adsorption,

chitosan

microparticles, ionic gelation, cadmium metals
Kata Kunci:

Adsorpsi, mikropartikel kitosan, gelasi ionik, logam cadmium

\section{Abstract}

Synthesis of Chitosan Microparticles with Ionic Gelation Process As Adsorbent Metal Cd (II) was performed. The method used was ionic gelation, which was the formation of chitosan microparticles based on ionic interactions between positive amine groups on chitosan and negative polyanion tripolyphosphate groups. The chitosan microparticles formed were then characterized using FTIR, BET and SEM. The optimum condition of adsorption was determined by $\mathrm{pH}$ 3-8 variation, contact time variation $15-75$ minutes and variation of metal ion concentration Cd (II) 20-100 ppm. Then the results were interpreted to the Langmuir isotherm equation to determine the maximum adsorption capacity of Cd (II) ions by the chitosan microparticles. The characterization results showed that chitosan microparticles particle size of $1 \%$ and $2 \%$ chitosan solutions were 15-115 $\mu \mathrm{m}$ and 30-220 $\mu \mathrm{m}$, respectively, and pore averages of $3.293 \mathrm{~nm}$ and 2,679 nm respectively. Based on the analysis, the optimum state of adsorption of chitosan microparticles from $1 \%$ and $2 \%$ chitosan solution to $\mathrm{Cd}$ (II) ions was at $\mathrm{pH} 5$ with contact time of 45 minutes and 60 minutes and obtained a maximum adsorption capacity of $28.01 \mathrm{mg} / \mathrm{g}$ and $29.94 \mathrm{mg} / \mathrm{g}$.

\section{Abstrak}

Sintesis Mikropartikel Kitosan dengan Proses Gelasi Ionik Sebagai Adsorben Logam Cd(II) telah dilakukan. Metode yang digunakan ialah gelasi ionik, yaitu pembentukan mikropartikel kitosan berdasarkan interaksi ionik antara gugus amina positif pada kitosan dengan gugus negatif polianion tripolifosfat. Mikropartikel kitosan yang terbentuk kemudian dikarakterisasi menggunakan FTIR, BET dan SEM. Kondisi optimum adsorpsi ditentukan melalui variasi pH 3-8, variasi waktu kontak 15-75 menit dan variasi konsentrasi ion logam Cd(II) 20-100 ppm. Kemudian hasilnya diinterpretasikan terhadap persamaan isoterm Langmuir untuk menentukan kapasitas adsorpsi maksimum ion Cd(II) oleh mikropartikel kitosan. Hasil karakterisasi menunjukkan bahwa ukuran partikel mikropartikel kitosan dari larutan kitosan $1 \%$ dan 2\% masing-masing sebesar 15-115 $\mu \mathrm{m}$ dan 30-220 $\mu \mathrm{m}$, serta ukuran rata-rata pori 3,293 nm dan 2,679 nm. Berdasarkan hasil analisis, keadaan optimum adsorpsi mikropartikel kitosan dari larutan kitosan $1 \%$ dan $2 \%$ terhadap ion Cd(II) adalah pada pH 5 dengan waktu kontak 45 menit dan 60 menit dan diperoleh kapasitas adsorpsi maksimum sebesar $28,01 \mathrm{mg} / \mathrm{g}$ dan $29,94 \mathrm{mg} / \mathrm{g}$.

\section{Pendahuluan}

Kandungan logam berat dalam suatu perairan dapat menyebabkan kontaminasi dan pencemaran terhadap lingkungan. Salah satu logam berat yang terdapat dalam perairan ialah logam kadmium. Kadmium merupakan salah satu logam berat yang paling banyak 
menimbulkan toksisitas pada makhluk hidup, hal tersebut disebabkan ion Cd(II) yang bersifat toksik dan dapat terakumulatif dalam tubuh [1].

Metode yang sering digunakan untuk menurunkan konsentrasi logam berat dalam perairan adalah adsorpsi. Adsorpsi merupakan metode yang sederhana dan memiliki kelebihan tersendiri sebagai adsorben, yaitu dapat memanfaatkan limbah-limbah organik sebagai biosorben, serta dapat diregenerasi kembali [2]. Salah satu yang marak dikembangkan saat ini adalah adsorpsi menggunakan biomolekul kitin. Kitin dapat ditransformasi menjadi kitosan dengan cara menghilangkan gugus asetil dalam proses deasetilasi [3].

Kitosan mempunyai reaktivitas kimia yang tinggi, sehingga dapat berperan sebagai penukar ion dan berfungsi sebagai adsorben ion logam berat. Pemanfaatan kitosan sebagai adsorben ion logam Cd(II) dianggap kurang maksimal, sehingga dilakukan penelitian lebih lanjut mengenai modifikasi kitosan. Serbuk kitosan dapat dimodifikasi menjadi bentuk mikropartikel kitosan untuk meningkatkan daya adsorpsi terhadap logam berat.

Pembentukan mikropartikel kitosan dapat dilakukan dengan beberapa metode, salah satunya ialah menggunakan metode gelasi ionik. Metode ini dilakukan dengan cara mencampurkan polimer kitosan dengan polianion sodium tripolifosfat. Harapan dari penelitian ini ialah untuk menghasilkan kitosan dengan ukuran mikro dengan luas permukaan yang besar, sehingga memungkinkan adanya interaksi permukaan yang lebih besar dalam adsorpsi ion logam, khususnya logam Cd(II).

\section{Metode Penelitian}

\section{Alat dan Bahan}

Alat-alat yang digunakan dalam penelitian ini, yaitu peralatan gelas, neraca analitik, magnetic stirrer, kertas saring. alumunium foil, freeze dryer, Fourier Transform InfraRed (FTIR), Brunauer, Emmet dan Teller (BET), Scanning Electron Microscopy (SEM) dan Atomic Adsorption Spectroscopy (AAS). Bahan-bahan yang digunakan pada penelitian ini, yaitu kitosan, akuades, NaTPP, $\mathrm{CH}_{3} \mathrm{COOH}$ p.a, $\mathrm{CdCl}_{2} .2 \mathrm{H}_{2} \mathrm{O}$ p.a, HCL p.a, dan $\mathrm{NaOH}$ p.a.

\section{Re-deasetilasi Kitosan}

Kitosan seberat $30 \mathrm{~g}$ direndam dalam $600 \mathrm{~mL} \mathrm{NaOH}$ $50 \%$, kemudian diaduk menggunakan magnetik stirrer dengan kecepatan sambil dilakukan pemanasan pada suhu $90^{\circ} \mathrm{C}$ selama 4 jam. Residu hasil penyaringan lalu dinetralkan melalui pencucian menggunakan akuades. Residu dikeringkan dalam oven pada suhu $80^{\circ} \mathrm{C}$ selama 5 jam. Kitosan hasil re-deasetilasi diuji derajat deasetilasinya menggunakan FTIR.

\section{Pembuatan Mikropartikel Kitosan dari Larutan Kitosan $1 \%$ dan $2 \%$}

Kitosan sebanyak 1 gram dan 2 gram dilarutkan dalam $100 \mathrm{~mL}$ asam asetat $1 \%$ sampai terbentuk larutan kitosan. Larutan kitosan yang terbentuk kemudian diambil sebanyak $50 \mathrm{~mL}$ lalu ditambahkan dengan 20 $\mathrm{mL}$ natrium tripolifosfat $1 \%$ tetes demi tetes sambil dilakukan pengadukan dalam magnetik stirrer. Gel yang terbentuk selanjutnya disentrifugasi dengan kecepatan 2000 rpm selama 30 menit. Residu kitosan yang diperoleh lalu dibekukan dengan freeze dryer.

\section{Karakterisasi Mikropartikel Kitosan}

Mikropartikel kitosan hasil sintesis kemudian dikarakterisasi menggunakan FTIR, BET dan SEM.

\section{Adsorpsi Ion Cd(II) Menggunakan Mikropartikel Kitosan}

\section{Penentuan pH Optimum}

Penentuan $\mathrm{pH}$ optimum dilakukan dengan mengkondisikan $25 \mathrm{~mL}$ larutan logam Cd 50 ppm menjadi $\mathrm{pH}$ 3-8 interval $\mathrm{pH} 1$ dengan penambahan HCI atau $\mathrm{NaOH}$. Larutan logam kemudian dipindahkan kedalam gelas beaker $100 \mathrm{~mL}$ yang telah berisi 0,3 gram mikropartikel kitosan dan diaduk dalam magnetik stirrer. Selanjutnya konsentrasi larutan diukur dengan AAS.

\section{Penentuan Waktu kontak Optimum}

Larutan Cd(II) 50 ppm sebanyak $25 \mathrm{~mL}$ diatur menjadi pH optimum. Larutan kemudian dipindahkan kedalam gelas beaker $100 \mathrm{~mL}$ yang telah berisi 0,3 gram mikropartikel kitosan, lalu diaduk menggunakan magnetik stirrer kecepatan dengan variasi waktu kontak 15-75 menit interval 15 menit, Selanjutnya konsentrasi larutan diukur dengan AAS.

\section{Variasi Konsentrasi Larutan Logam Cd(II)}

Larutan Cd(II) sebanyak $25 \mathrm{~mL}$ divariasikan pada konsentrasi 20-100 ppm interval 20 ppm yang telah dikondisikan pada $\mathrm{pH}$ optimum. Larutan kemudian dimasukan ke dalam erlenmeyer $250 \mathrm{~mL}$ yang telah berisi 0,3 gram mikropartikel kitosan, lalu diaduk menggunakan magnetik stirrer kecepatan 250 rpm selama waktu kontak optimum. Selanjutnya disaring dan konsentrasi larutan diukur menggunakan AAS.

\section{Hasil dan Pembahasan}

\section{Re-deasetilasi Kitosan}

Re-deasetilasi kitosan dilakukan untuk meningkatkan derajat deasetilasi dari kitosan. Dengan meningkatnya derajat deasetilasi kitosan, maka kandungan gugus $\mathrm{NH} 2$ dalam kitosan akan semakin banyak, sehingga diharapkan akan meningkatkan kemampuan kitosan untuk berikatan dengan ion tripolifosfat. Hasil spektrum FTIR dari kitosan hasil redeasetilasi dapat dilihat pada Gambar 1. 


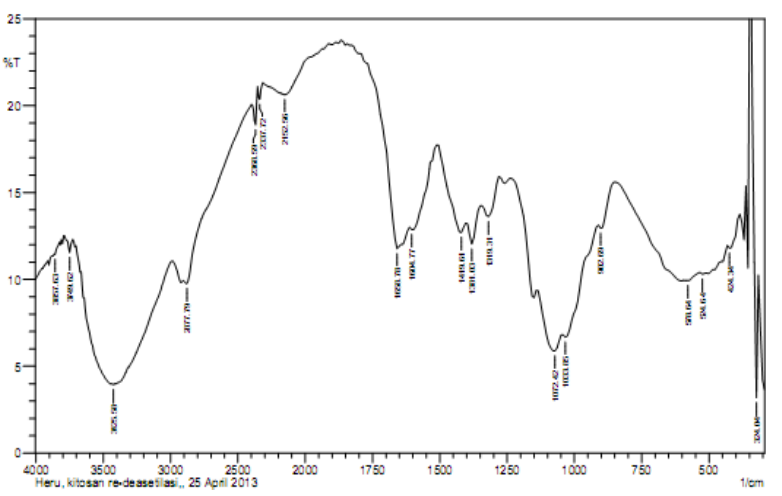

Gambar 1. Spektra FTIR kitosan

Berdasarkan spektra tersebut, diperoleh derajat deasetilasi kitosan hasil re-deasetilasi sebesar 69,9\%.

\section{Pembuatan Mikropartikel Kitosan}

Kitosan dimodifikasi menjadi mikropartikel kitosan dengan metode gelasi ionik bertujuan untuk meningkatkan kemampuan kitosan dalam mengadsorpsi logam berat. Kitosan dilarutkan terlebih dahulu dalam asam asetat $1 \%$ sehingga terbentuk larutan kitosan. Asam asetat akan memprotonasi gugus amina pada kitosan menjadi gugus $\mathrm{NH}_{3}{ }^{+}$. Pembentukan butiran partikel dilakukan dengan penetesan larutan natrium tripolifosfat $1 \%$ pada larutan kitosan sambil diaduk dengan magnetik stirer pada kecepatan tinggi. Larutan selanjutnya disentrifugasi untuk memisahkan larutan asetat dengan endapan kitosan-tripolifosfat. Endapan kitosan-tripolifosfat lalu dibekukan dengan freeze dryer di dalam ruang pembeku vakum hingga terbentuk mikropartikel kitosan. Menurut Lee $d k k$. [4], pembentukan ikatan kitosan dengan ion tripolifosfat dapat diprediksikan sebagai berikut :

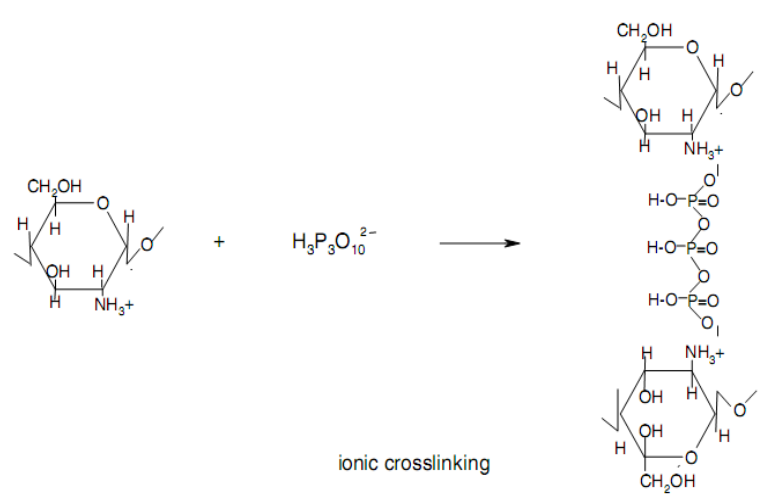

Gambar 2 Ikatan silang antara Kitosan dan natrium tripolifosfat

Karakterisasi Mikropartikel Kitosan dengan FTIR, BET dan SEM

Perbedaan gugus fungsi dalam kitosan dengan mikropartikel kitosan dapat dilihat dari spektra FTIR yang dihasilkan

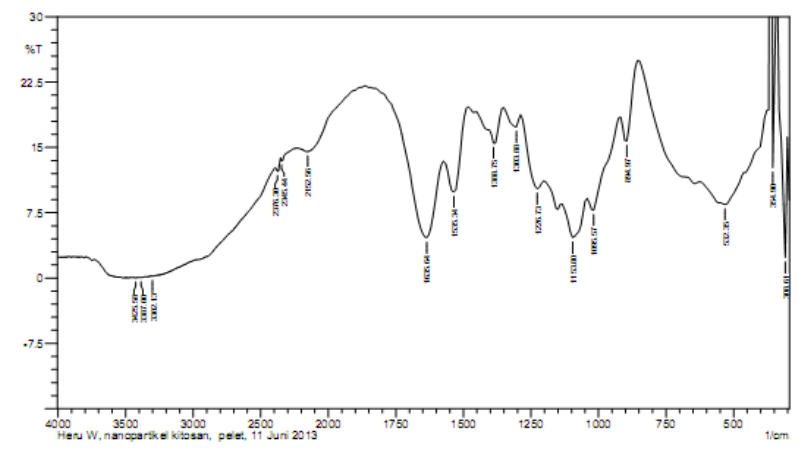

Gambar 3. Spektra FTIR dari Mikropartikel kitosan

Pada spektra FTIR mikropartikel kitosan terdapat puncak serapan baru pada bilangan gelombang 1153,8 $\mathrm{cm}^{-1}$ yang menunjukan adanya gugus fungsi $\mathrm{P}=\mathrm{O}$ dari ion tripolifosfat.

Mikropartikel kitosan hasil sintesis, kemudian dikarakterisasi menggunakan BET (Brunauer, Emmet dan Teller) untuk menentukan ukuran rata pori, luas permukaan dan volume total pori. Berdasarkan hasil karakterisasi BET, mikropartikel kitosan dari larutan kitosan $1 \%$ memiliki ukuran rata-rata pori sebesar $3,2926 \mathrm{~nm}$, luas permukaan $1,268 \mathrm{~m}^{2} / \mathrm{g}$ dan volume total pori $2,118 \times 10^{-3}(\mathrm{cc} / \mathrm{g})$, sedangkan pada mikropartikel kitosan dari larutan kitosan 2\% sebesar 2,6686 nm, $1,587 \mathrm{~m}^{2} / \mathrm{g}$ dan $1,465 \times 10-3$ (cc/g).

Selanjutnya mikropartikel kitosan dikarakterisasi menggunakan SEM untuk melihat bentuk morfologi dan ukuran partikel dari mikropartikel kitosan

(a)

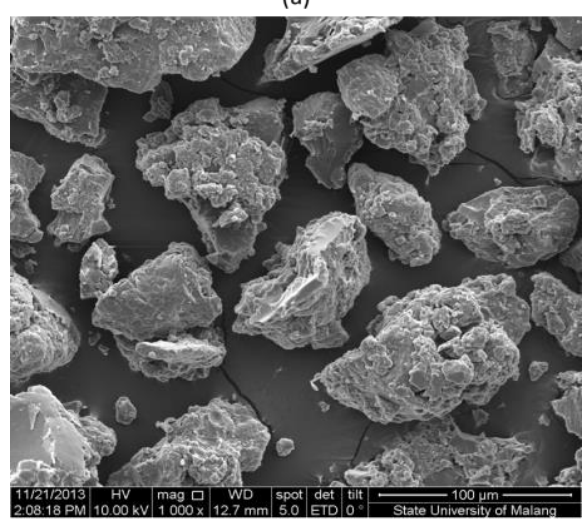

(b)



Gambar 4. Hasil SEM (a) mikropartikel kitosan dari larutan kitosan $1 \%$ dan (b) mikropartikel kitosan dari larutan kitosan $2 \%$ 
Berdasarkan hasil analisis SEM diketahui ukuran partikel mikropartikel kitosan dari larutan kitosan $1 \%$ berkisar antara 15-115 $\mu \mathrm{m}$, sedangkan pada mikropartikel kitosan dari larutan kitosan $2 \%$ memiliki ukuran partikel berkisar antara 30-220 $\mu \mathrm{m}$. Ukuran partikel tersebut menandakan bahwa mikropartikel kitosan hasil sintesis masuk dalam rentang ukuran partikel mikropartikel (1-1000 $\mu \mathrm{m})$.

\section{Adsorpsi Ion Cd(II) oleh Mikropartikel Kitosan}

\section{Penentuan pH Optimum}

Pengaruh pH terhadap adsorpsi Cd(II) dilakukan pada larutan Cd(II) 50 ppm variasi pH 3-8 interval pH 1, dengan waktu kontak 30 menit. Adanya pengaruh $\mathrm{pH}$ terhadap adsorpsi ion Cd(II) oleh mikropartikel kitosan dapat dilihat dari Gambar 5.



Gambar 5. Grafik adsorpsi ion logam Cd(II) pada variasi $\mathrm{pH}$

Berdasarkan hasil analisis didapatkan kondisi $\mathrm{pH}$ optimum kitosan re-deasetilasi terjadi pada $\mathrm{pH} 7$, sedangkan pada mikropartikel kitosan dari larutan kitosan $1 \%$ dan $2 \%$ diperoleh pH optimum 5 . Keadaan ini dimungkinkan karena pada keadaan $\mathrm{pH}$ optimum jumlah proton $\mathrm{H}^{+}$dan ion $\mathrm{OH}^{-}$dalam larutan tidak terlalu banyak dan relatif seimbang sehingga gugus aktif kitosan akan lebih optimum berikatan dengan ion Cd(II).

\section{Penentuan Waktu kontak Optimum}

Penentuan waktu kontak optimum bertujuan untuk mengetahui seberapa lama waktu yang dibutuhkan adsorben dalam menjerap ion logam Cd(II) secara optimum. Penelitian ini dilakukan dengan variasi waktu kontak 15-75 menit interval 15 menit, yang dilakukan pada $\mathrm{pH} 5$ ( $\mathrm{pH}$ optimum). Adanya pengaruh waktu kontak terhadap adsorpsi ion Cd(II) dapat dilihat pada Gambar 6.

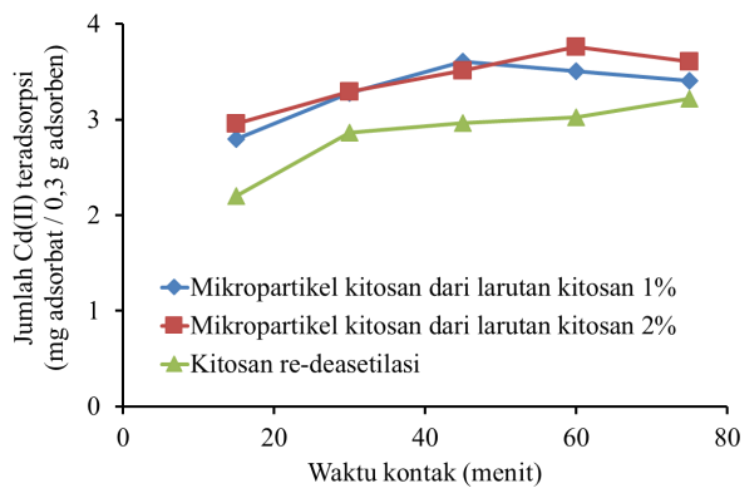

Gambar 6. Grafik adsorpsi ion logam Cd(II) pada variasi waktu

Kondisi waktu kontak optimum mikropartikel kitosan dari larutan kitosan $1 \%$ terjadi pada waktu kontak 45 menit, sedangkan pada mikropartikel kitosan dari larutan kitosan $2 \%$ terjadi pada waktu kontak 60 menit

\section{Pengaruh Konsentrasi Larutan logam}

Pengaruh konsentrasi dilakukan pada larutan Cd(II) dengan variasi konsentrasi 20-100 ppm interval 20 ppm yang dikondisikan pada $\mathrm{pH} 5$ ( $\mathrm{pH}$ optimum), dalam pengadukan magnetik stirrer pada waktu kontak optimum. dapat dilihat pada Gambar 7.

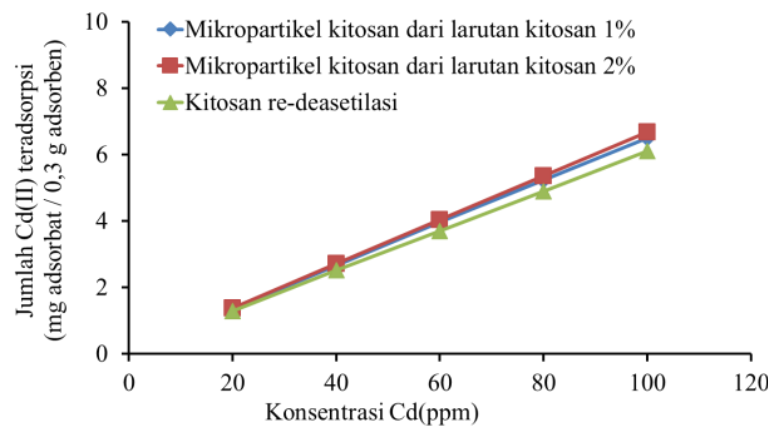

Gambar 7. Grafik adsorpsi ion logam Cd(II) pada variasi konsentrasi

Hasil adsorpsi ion Cd(II) mengalami peningkatan sebanding dengan penambahan konsentrasi awal larutan logam. Semakin besar konsentrasi larutan logam maka kemampuan adsorpsi mikropartikel kitosan semakin meningkat, sampai semua gugus aktif adsorben terisi oleh adsorbat.

\section{Penentuan Kapasitas Adsorpsi Maksimum}

Kapasitas adsorpsi maksimum diketahui dengan meginterpretasikan terhadap isoterm Langmuir, sehingga diperoleh persamaan garis seperti pada Gambar 8 yang menunjukan nilai kapasitas adsorpsi 
(a)

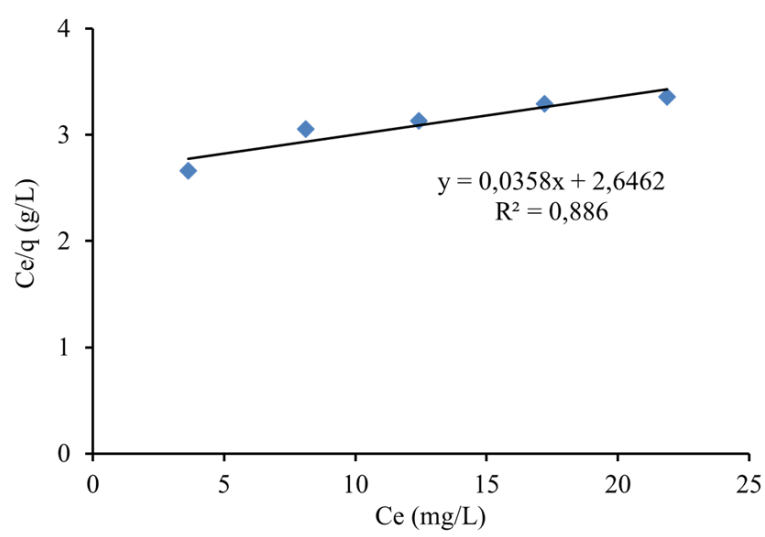

(b)

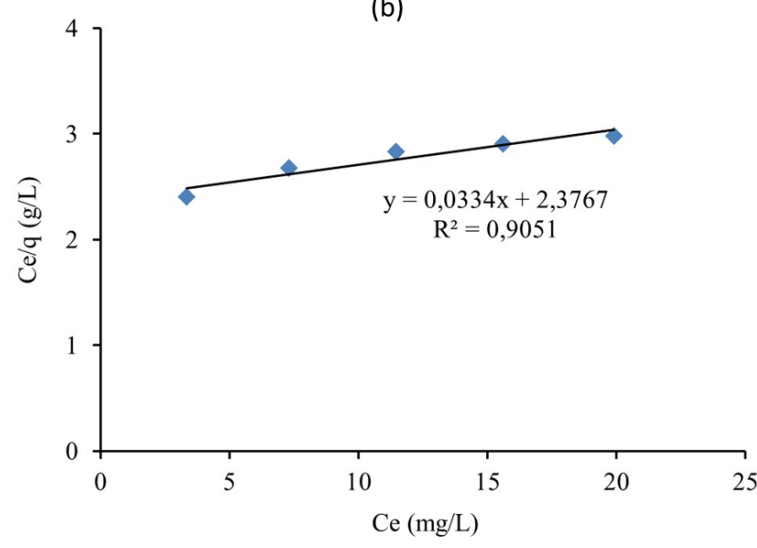

Gambar 8. Grafik isoterm Langmuir (a) mikropartikel kitosan dari larutan kitosan $1 \%$ dan (b) mikropartikel kitosan dari larutan kitosan $2 \%$

Grafik isoterm Langmuir, menunjukan adanya persamaan garis yang dapat digunakan untuk menghitung kapasitas adsorpsi maksimum ion Cd(II) oleh adsorben mikropartikel kitosan. Nilai kapasitas adsorpsi ion Cd(II) pada mikropartikel kitosan dari larutan kitosan $1 \%$ dan $2 \%$ masing-masing sebesar $28,01 \mathrm{mg} / \mathrm{g}$ dan $29,94 \mathrm{mg} / \mathrm{g}$.

\section{Kesimpulan}

Mikropartikel kitosan dari larutan kitosan 1\% dan $2 \%$ diperoleh dengan ukuran partikel masing-masing sebesar 15-115 $\mu \mathrm{m}$ dan 30-220 $\mu \mathrm{m}$, serta ukuran ratarata pori 3,2926 nm dan 2,6686 $\mathrm{nm}$. Keadaan optimum adsorpsi mikropartikel kitosan dari larutan kitosan $1 \%$ dan $2 \%$ terhadap ion $\mathrm{Cd}$ (II) ialah pada $\mathrm{pH} 5$ dengan waktu kontak 45 menit dan 60 menit. Kapasitas adsorpsi ion $\mathrm{Cd}(\mathrm{II})$ pada mikropartikel kitosan dari larutan kitosan $1 \%$ dan $2 \%$ masing-masing sebesar $28,01 \mathrm{mg} / \mathrm{g}$ dan $29,94 \mathrm{mg} / \mathrm{g}$.

\section{Daftar Pustaka}

[1] Darjito Darjito, Danar Purwonugroho, Siti Nasirotun Nisa, Study On Adsorption Of Cd(II) By ChitosanAlumina, Indonesian Journal of Chemistry, 6, 3, (2010) 238-244 http://dx.doi.org/10.22146/ijc.311

[2] Harry Agusnar, Penggunaan Kitosan Dari Tulang Rawan Cumi-Cumi (Loligo Pealli) Untuk Menurunkan Kadar Ion Logam Cd Dengan
Menggunakan Spektrofotometri Serapan Atom, (2010)

[3] LH Rahayu, S Purnavita, Optimasi pembuatan kitosan dari kitin limbah cangkang rajungan (Portunus pelagicus) untuk adsorben ion logam merkuri, Reaktor, 11, 1, (2007) 45-49

[4] Sung-Tao Lee, Fwu-Long Mi, Yu-Ju Shen, ShinShing Shyu, Equilibrium and kinetic studies of copper (II) ion uptake by chitosan-tripolyphosphate chelating resin, Polymer, 42, 5, (2001) 1879-1892 http://dx.doi.org/10.1016/S0032-3861(00)00402-X 